\title{
Fracture Behavior of Alumina/Monazite Multilayer Laminates
}

\author{
Jennifer R. Mawdsley, ${ }^{* \dagger}$ Desiderio Kovar, ${ }^{* \neq}$ and John W. Halloran* \\ Materials Science and Engineering Department, University of Michigan, Ann Arbor, Michigan 48019-2136
}

\begin{abstract}
Monazite $\left(\mathrm{LaPO}_{4}\right)$ has been proposed as an interphase to promote debonding between the reinforcement and the matrix during the fracture of oxide-based composites. The correlation between fracture behavior and micromechanical properties in model alumina/monazite $\left(\mathrm{Al}_{2} \mathrm{O}_{3} / \mathrm{LaPO}_{4}\right)$ multilayer laminates has been investigated in this study. The delamination fracture energy $\left(\Gamma_{\mathrm{i}}\right)$ was dependent on crack length, which is consistent with previous results; the initial value of $\Gamma_{i}$ was $\sim 10 \mathrm{~J} / \mathrm{m}^{2}$. The interfacial frictional sliding resistance increased as the normal stress on the interface increased. Using a Coulombic friction model, the coefficient of static friction between the $\mathrm{Al}_{2} \mathrm{O}_{3}$ and $\mathrm{LaPO}_{4}$ layers was determined to be 0.63 . The influence of $\Gamma_{i}$ and flaw size in the $\mathrm{Al}_{2} \mathrm{O}_{3}$ layers on fracture path has been predicted, using an existing model, and confirmed experimentally. The results indicate that, in addition to satisfying energybased fracture criteria, several other factors affect whether $\mathrm{LaPO}_{4}$ is a suitable interphase for oxide composites.
\end{abstract}

\section{Introduction to the Alumina/Monazite System}

$\mathrm{D}$ AMAGE-TOLERANT ceramic-matrix composites (CMCs) require that crack deflection and extensive delamination occur between the matrix and reinforcement during fracture. This process, in current CMCs, is achieved by placing interphases that promote debonding between the reinforcement and the matrix. However, current interphases (BN or carbon) used with non-oxide fibers ${ }^{1-3}$ are not suitable for oxide composites, because of problems with high-temperature oxidation and chemical reaction with the environment, the matrix, or the reinforcement. So far, the necessary combination of properties required for interphases in oxide composites, including low adhesion to oxide reinforcement materials and chemical compatibility, has been difficult to achieve.

Recently, Morgan and Marshall ${ }^{4}$ investigated a variety of compounds that were believed to be compatible with oxide reinforcements, and they observed that monazite $\left(\mathrm{LaPO}_{4}\right)$ showed promise in deflecting cracks in composites made with an alumina $\left(\mathrm{Al}_{2} \mathrm{O}_{3}\right)$ reinforcement. The phase stability of the $\mathrm{LaPO}_{4} / \mathrm{Al}_{2} \mathrm{O}_{3}$ system has since been demonstrated in several studies that show that $\mathrm{LaPO}_{4}$ and $\mathrm{Al}_{2} \mathrm{O}_{3}$ are chemically compatible at temperatures as high as $1750^{\circ} \mathrm{C}$, if the $\mathrm{LaPO}_{4}$ is stoichiometric and excess carbon is not present. ${ }^{5-7}$ However, contradictory evidence remains as to whether the $\mathrm{LaPO}_{4} / \mathrm{Al}_{2} \mathrm{O}_{3}$ interface is sufficiently weak to promote debonding during fracture. ${ }^{8}$

In this study, micromechanical properties (interfacial fracture energy and the interfacial frictional sliding resistance) are measured in model $\mathrm{LaPO}_{4} / \mathrm{Al}_{2} \mathrm{O}_{3}$ laminates in an effort to determine

M. Thouless-contributing editor

Manuscript No. 189421. Received April 15, 1999; approved September 12, 1999. Supported by DARPA, administered by the U.S. Office of Naval Research, under Supported by DARPA, adminis
Contract No. N0014-95-0302.

${ }^{*}$ Member, American Ceramic Society.

Currently with Dept. of Materials Science and Engineering, Northwestern University, Evanston, IL 60208.

Currently with Texas Materials Institute and Mechanical Engineering Dept., University of Texas at Austin, Austin, TX 78712-1063. the conditions that are necessary for crack deflection at the interface between alumina and monazite. Based on these measurements, a correlation is proposed between these micromechanical properties and the corresponding fracture behavior in $\mathrm{LaPO}_{4} /$ $\mathrm{Al}_{2} \mathrm{O}_{3}$ multilayer laminates.

\section{Experimental Procedure}

\section{(1) Sample Fabrication}

Three-layer or multilayer laminates were fabricated by sequentially stacking individual layers of alumina (RC-HP DBM without $\mathrm{MgO}, 99.96 \%$ pure, Reynolds, Richmond, VA) and monazite. In some cases, 4 vol\% of tetragonal yttria-partially stabilized zirconia (TZ-3Y, 99.8\% pure, Tosoh, Bound Brook, NJ) was dispersed in the alumina layers to control grain growth. The monazite was provided in the form of a rhabdophane $\left(\mathrm{LaPO}_{4} \cdot x \mathrm{H}_{2} \mathrm{O}\right)$ slurry, which was converted to monazite by heating in air to $900^{\circ} \mathrm{C}$. Details of the procedure that was used to synthesize the rhabdophane are presented elsewhere.,

Four $75 \mathrm{~mm} \times 50 \mathrm{~mm}$ billets and one $50 \mathrm{~mm} \times 25 \mathrm{~mm}$ billet were fabricated with different architectures. Billets 1 and 2 consisted of three layers: a thin monazite layer sandwiched between much-thicker alumina layers. Billets 3 and 4 were multilayer alumina/monazite laminates that consisted of $\sim 44-54$ alternating layers of alumina and monazite. Billet 5 was made by stacking 33 alumina-only layers. The alumina in billets 1,4 , and 5 contained a zirconia grain-growth inhibitor, whereas the alumina in billets 2 and 3 did not.

The layers were made either by tape casting ${ }^{9}$ or by molding a thermoplastic mixture ${ }^{10}$ into a thin sheet. Then, the individual layers were laminated at $130^{\circ} \mathrm{C}$ in a steel die to form a solid billet. The polymer binder then was removed via pyrolysis by slow heating under flowing nitrogen. Following pyrolysis, samples were subsequently heated to $750^{\circ} \mathrm{C}$ for $2 \mathrm{~h}$ in air to remove residual carbon. Samples were hot-pressed using a graphite die coated with alumina, at $1400^{\circ} \mathrm{C}$ in a nitrogen atmosphere for $1-1.5 \mathrm{~h}$ under a pressure of $30 \mathrm{MPa}$ to densify the laminates. Finally, the billets were surface-ground to reduce their thickness and/or make them flat, and then they were machined into bars. A summary of the compositions and architectures of the five billets is shown in Table I.

\section{(2) Measurement of Delamination Fracture Energy}

The delamination fracture energy $\left(\Gamma_{\mathrm{i}}\right)$ was measured using a notched-beam bend test, based on a test developed by Charalambides et al. ${ }^{11}$ in which a bar with a rectangular cross section and an interface oriented parallel to the long axis of the bar is loaded in four-point flexure. However, rather than use a bilayer specimen as originally proposed, three-layer or multilayer laminate specimens that consisted of a thin layer of monazite $(\sim 200 \mu \mathrm{m}$ for the three-layer samples, $\sim 15 \mu \mathrm{m}$ for the multilayer samples) sandwiched between much-thicker layers of alumina $(\sim 2 \mathrm{~mm}$ for the three-layer samples, $\sim 150 \mu \mathrm{m}$ for the multilayer samples) were used.

A major advantage of the specimen configurations used in this study is that, unlike a bilayer specimen, residual stresses do not significantly impact the driving force for delamination and, therefore, do not affect the measurement of delamination resistance. 
Table I. Sample Fabrication Details

\begin{tabular}{|c|c|c|c|c|c|c|c|c|}
\hline \multirow[b]{2}{*}{ Billet } & \multirow{2}{*}{\multicolumn{2}{|c|}{ Size }} & \multirow[b]{2}{*}{ Constituent(s) } & \multirow[b]{2}{*}{ Architecture } & \multicolumn{2}{|c|}{ Fabrication $^{\S}$} & \multirow{2}{*}{$\begin{array}{l}\text { As-pressed layer, } \\
\text { thickness }\end{array}$} & \multirow{2}{*}{$\begin{array}{l}\text { As-pressed billet } \\
\text { thickness (mm) }\end{array}$} \\
\hline & & & & & $\mathrm{LaPO}_{4}$ & $\mathrm{Al}_{2} \mathrm{O}_{3}$ & & \\
\hline 1 & $25 \mathrm{~mm}$ & $\times 50 \mathrm{~mm}$ & $\mathrm{Al}_{2} \mathrm{O}_{3},{ }^{\dagger} \mathrm{LaPO}_{4}$ & Sandwich & TM & TM & $\mathrm{LaPO}_{4}, 210 \mu \mathrm{m}$ & 5.18 \\
\hline 4 & $75 \mathrm{~mm}$ & $\times 50 \mathrm{~mm}$ & $\mathrm{Al}_{2} \mathrm{O}_{3}{ }^{\dagger} \mathrm{LaPO}_{4}$ & Laminate & $\mathrm{TC}$ & $\mathrm{TC}$ & $\mathrm{LaPO}_{4}, 15 \mu \mathrm{m} ; \mathrm{Al}_{2} \mathrm{O}_{3}, 125 \mu \mathrm{m}$ & 7.27 \\
\hline 5 & $75 \mathrm{~mm}$ & $\times 50 \mathrm{~mm}$ & $\mathrm{Al}_{2} \mathrm{O}_{3}^{\dagger}$ only & Monolith & & $\mathrm{TC}$ & $\mathrm{Al}_{2} \mathrm{O}_{3}, 150 \mu \mathrm{m}$ & 4.88 \\
\hline
\end{tabular}

${ }^{\dagger} \mathrm{Al}_{2} \mathrm{O}_{3}$ contains 4 vol\% of Y-TZP, which was added to inhibit grain growth. "The term "sandwich" means that one layer of monazite has been placed between two layers of alumina. "TM" denotes thermoplastic mixture, and "TC" denotes tape cast.

This situation can be observed in Fig. 1, where schematic illustrations of the three testing configurations considered are shown. When residual stresses that result from thermal expansion mismatch cause delamination in a sample with two or more dissimilar layers, the steady-state driving force can be obtained by determining the difference between the strain energy stored in the specimen behind and far ahead of the crack tip. In a two-layer sample (Figs. 1(a) and (b)) with a crack propagating along the interface, the strain energy behind the crack tip has been released and, thus, is zero; however, the strain energy ahead of the crack tip is still stored in the sample. Therefore, this energy difference is available, along with applied loads, to drive the delamination crack. In a sandwich specimen with a compliant middle layer (Figs. 1(c) and (d)) or a multilayer sample (Figs. 1(e) and (f)), the layers are still bonded to and constrained by other layers after delamination. Thus, the strain energy ahead of and behind the crack tip is constant, resulting in zero driving force from residual stresses for delamination. ${ }^{12}$ Thus, the large residual stress present in the layers does not significantly affect the driving force for delamination, as long as the notch is not cut too deep or too shallow.

For the notched-beam bend test, a notch $200 \mu \mathrm{m}$ wide was cut into the bottom surface of a specimen oriented perpendicular to the interface. The notch was approximately half of the total sample height (see Table II) and approached, but did not penetrate, the thin monazite layer. Then, a crack was initiated from the notch tip by bending the sample in a three-point bend fixture that was mounted on a screw-driven mechanical testing machine (Model 4483, Instron Corp., Canton, MA). Fully articulated three-point and four-point bend fixtures were used in all tests that were conducted with the mechanical testing machine, to minimize friction between the loading pins and the specimen surface. ${ }^{\S}$ The testing machine was operated under displacement control at a crosshead speed of $0.1 \mathrm{~mm} / \mathrm{min}$, with a linear variable displacement transducer (LVDT) deflectometer (resolution of $\pm 0.2 \mu \mathrm{m}$ ) contacting the bottom surface of the specimen to measure the center-point specimen deflection. After precracking, the sample was placed in a fully articulated four-point bend fixture and the sample was loaded until the crack intersected and propagated along the alumina/monazite interface. The load necessary to propagate the delamination crack was measured, and then the sample was unloaded and removed from the testing frame so that the crack lengths could be measured via optical microscopy, using a reduced aperture method that illuminates cracks with internally scattered light. ${ }^{13}$ (Some samples also were measured via scanning electron microscopy (SEM) after testing, and the results were in good agreement with the results from the optical method.) This process of loading until crack propagation occurred, unloading, and using optical microscopy for crack measurement was repeated until the cracks propagated beyond the inner loading points or into the alumina layer. The crack never extended beyond the inner loading points on the first iteration of this process; all the samples were subjected to at least three iterations before the crack propagated beyond the inner loading points or into the alumina. Measurements made when the delamination crack was propagating between the

${ }^{\S}$ When monolithic steel beams were placed in these fixtures and tested, friction was indeed negligible. These results have been published elsewhere. ${ }^{14}$

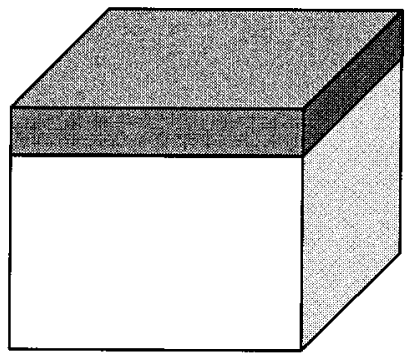

(a)

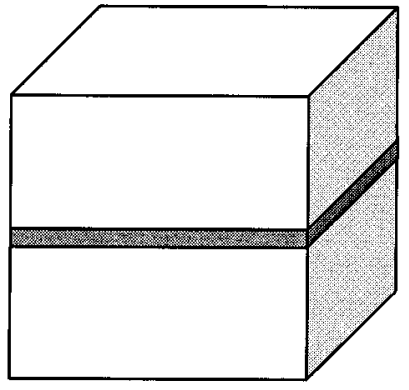

(c)

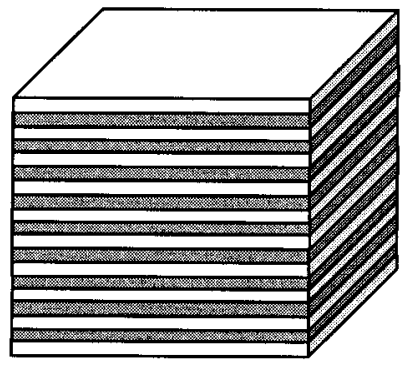

(e)

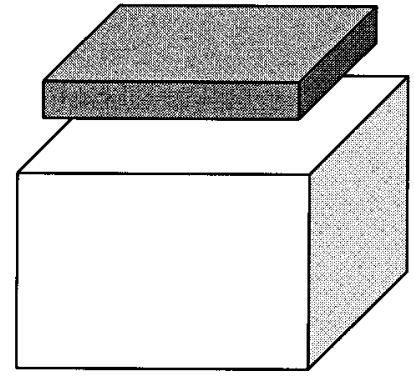

(b)

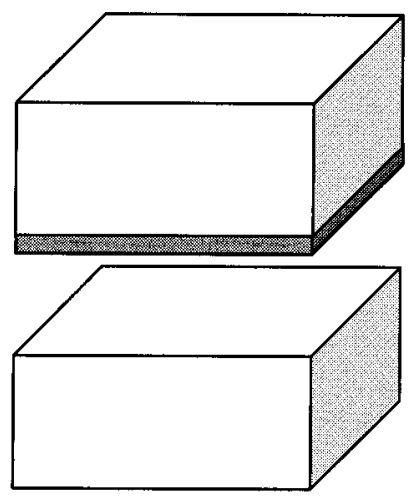

(d)

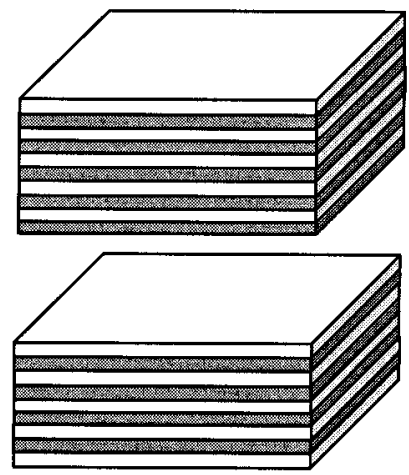

(f)
Fig. 1. Bilayer samples (a) before delamination and (b) after delamination; the darker top layer has shrunk because it is not being constrained by the lighter bottom layer anymore. Figures 1(c) and (d) respectively, show sandwich specimens before and after delamination; the darker layer is still constrained by a lighter layer. Figures 1(e) and (f) respectively show multilayer laminates before and after delamination; the darker layers are still constrained by the lighter layers. 
Table II. Notched-Beam Bend-Test Results

\begin{tabular}{|c|c|c|c|c|c|}
\hline \multirow[b]{2}{*}{ Sample } & \multirow[b]{2}{*}{ Billet } & \multirow[b]{2}{*}{$\begin{array}{l}\text { Total sample } \\
\text { height }(\mathrm{mm})\end{array}$} & \multirow[b]{2}{*}{$\begin{array}{l}\text { Notch height } \\
\quad(\mathrm{mm})\end{array}$} & \multicolumn{2}{|c|}{ Delamination fracture energy, $\Gamma_{\mathrm{i}}\left(\mathrm{J} / \mathrm{m}^{2}\right)$} \\
\hline & & & & $\begin{array}{c}\text { Measured at shortest } \\
\text { delamination crack length }\end{array}$ & $\begin{array}{c}\text { Measured at longest } \\
\text { delamination crack length }\end{array}$ \\
\hline 1 & 1 & 4.09 & 1.65 & 9.7 & 17.6 \\
\hline 2 & 2 & 4.97 & 2.33 & 13.5 & 21.5 \\
\hline 3 & 3 & 4.03 & 2.15 & 14.6 & 15.2 \\
\hline
\end{tabular}

inner and outer loading points were disregarded. In the case of the multilayer sample (sample 3 ), the crack propagated along only one interface.

The delamination fracture energy $\Gamma_{i}$ of the samples was calculated using the equation

$$
\Gamma_{\mathrm{i}}=\left[\frac{3 P^{2} L^{2}\left(1-v^{2}\right)}{2 E\left(h_{1}+h_{2}\right)^{3} b^{2}}\right]\left[\left(\frac{h_{1}}{h_{2}}+1\right)^{3}-1\right]
$$

where $P$ is the load needed to cause debonding, $L$ the distance from the outer load span to the inner load span $(10 \mathrm{~mm}), v$ the Poisson's ratio of the bulk material (alumina), and $E$ the Young's modulus of alumina. The variables $h_{1}$ and $h_{2}$ are the heights of the lower and upper beams, respectively (the notch always being in the lower beam), and $b$ is the width of the beam.

\section{(3) Measurement of Interfacial Frictional Sliding Resistance}

Specimens for the measurement of interfacial frictional sliding resistance $\left(\tau_{\mathrm{s}}\right)$ were obtained by cutting a notch through the end of the bar, parallel to the plane of the monazite/alumina interface and into a monazite layer. Wedges were inserted into the notches far enough to initiate a delamination crack. Then, the wedges were removed from these samples, a razor blade was inserted into the notch, and a Mode I force was applied to split the specimen in two parts along the interface between the alumina and monazite. The two pieces of the sample then were reassembled and placed into a fully articulated, three-point bend fixture that was mounted on a screw-driven test machine. The testing machine was operated in the same manner as described previously with the LVDT deflectometer directly beneath the loading point. The specimen was loaded until a nonlinearity was detected in the load-deflection response that corresponded to the point where slipping occurred along the cracked interface. Then, the sample was partially unloaded until slipping began in the opposite direction. A series of load-unload loops were generated and plotted individually to analyze sliding resistance. Using the model of Kovar and Thouless, ${ }^{14}$ and considering machine compliance, the interfacial frictional sliding resistance was calculated from the relation

$$
\tau_{\mathrm{s}}=\frac{3(\Delta P) h_{1} h_{2}}{b\left(h_{1}+h_{2}\right)^{3}}
$$

where $\Delta P$ is the difference between the load at which slipping began and the minimum load during a load-unload cycle.

\section{(4) Fracture Behavior of \\ Alumina/Monazite Multilayer Laminates}

Several bars made from multilayer bars were tested from billets 3,4 , and 5 by loading samples in four-point flexure. The tensile surface of each bar was polished and chamfered prior to testing. In some cases, a notch $200 \mu \mathrm{m}$ wide and approximately half the height of the bar was cut into the tensile surface of the specimen perpendicular to the long axis of the bar, using a diamond-edged wafering blade. In all cases, the testing machine was operated in displacement control at a crosshead speed of $0.5 \mathrm{~mm} / \mathrm{min}$.

\section{Results}

\section{(1) Sample Characterization}

To ensure that no reactions occurred between the monazite and the alumina, ${ }^{6,8,15}$ the samples were inspected via SEM and X-ray diffractometry (XRD) was performed for phase identification. No reaction phases were observed in the powder XRD spectra or the micrograph of the interface region that is shown in Fig. 2. The thicknesses of the monazite layer in billets 1 and 2 are 210 and 160 $\mu \mathrm{m}$, respectively. The thickness of the monazite layers in billets 3 and 4 was $15 \mu \mathrm{m}$, and the thickness of the alumina layers was 125-150 $\mu \mathrm{m}$. The densities of the bars cut from these billets were measured using the Archimedes method, according to a standard method. ${ }^{16}$ The average measured density of bars from billets 3 and 4 were 4.04 and $4.10 \mathrm{~g} / \mathrm{cm}^{3}$, respectively, which is $99.0 \%-99.9 \%$ of theoretical density, assuming that the samples contained 10 vol\% monazite. The average measured density of bars from billet 5 was $4.04 \mathrm{~g} / \mathrm{cm}^{3}$, which is $99.6 \%$ of theoretical density for an alumina sample that contains $4 \mathrm{vol} \%$ Y-TZP.

\section{(2) Interfacial Fracture Energy Measurements}

A representative plot of load versus specimen deflection (measured using the LVDT deflectometer) for the notched-beam bend test is shown in Fig. 3. The corresponding $\Gamma_{\mathrm{i}}$ values, which are in the range of $9.7-14.6 \mathrm{~J} / \mathrm{m}^{2}$ at the shortest crack lengths $(\sim 3 \mathrm{~mm})$, are summarized in Table II for billets 1-3. Compared to the earlier results of Morgan and Marshall ${ }^{7}$ on similar materials, these values are slightly greater.

Figure 3 indicates that the applied load necessary to drive delamination steadily increases, even when the crack is within the inner loading span. The increasing load implies that the interfacial fracture energy is dependent on crack length ( $R$-curve behavior). $R$-curve behavior in the delamination fracture energy has been observed in earlier work ${ }^{7}$ and may be responsible for the significant variability in the measured value of $\Gamma_{i}$ in the alumina/ monazite system.

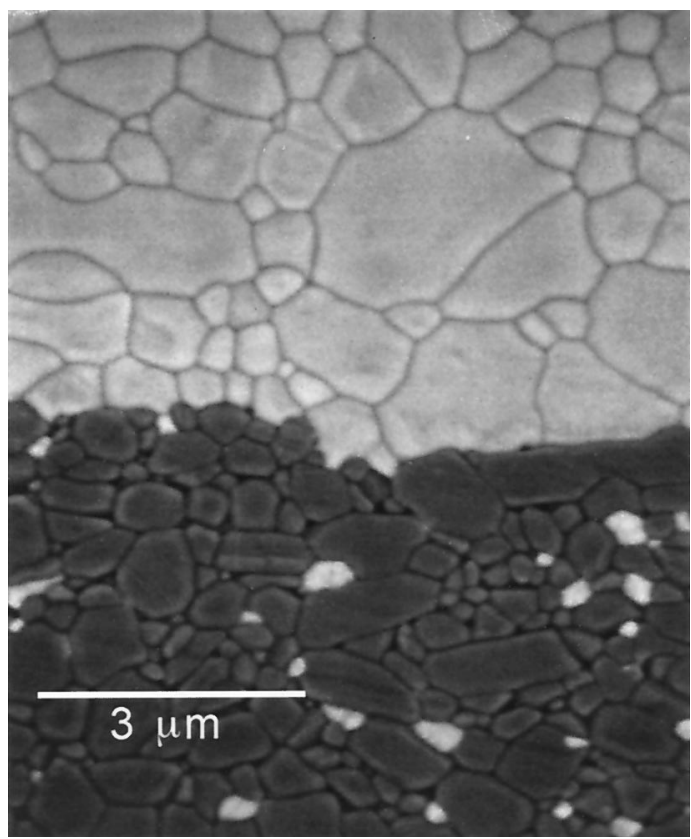

Fig. 2. Backscattered SEM micrograph of a thermally etched alumina/ monazite interface, showing that no reaction phases have formed; the bright phase in the upper region is $\mathrm{LaPO}_{4}$, the dark phase in the lower region is $\mathrm{Al}_{2} \mathrm{O}_{3}$, and the bright inclusions in the $\mathrm{Al}_{2} \mathrm{O}_{3}$ matrix are $\mathrm{ZrO}_{2}$ particles. 


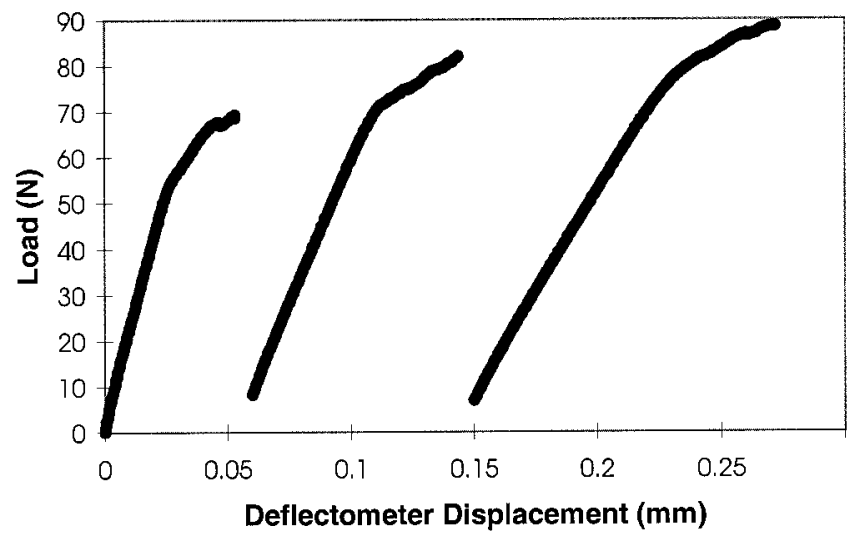

Fig. 3. Load-versus-specimen-deflection data from a notched-beam bend test conducted on a three-layer sandwich specimen.

\section{(3) Interfacial Frictional-Sliding-Resistance Measurements}

A series of load-unload cycles taken during a frictional sliding resistance test is shown in Fig. 4. The hysteresis increases as the maximum load increases, which indicates that $\tau_{\mathrm{s}}$ increases as the normal stress acting on the interface increases. The normal stress is calculated by dividing the load by the interfacial area and is plotted versus the interfacial frictional sliding resistance in Fig. 5. At low normal stresses, the sliding displacements are small and the interfacial frictional sliding resistance is very low $(\sim 0.06 \mathrm{MPa})$. As the loads are increased, the sliding displacements increase, which forces asperities on the sliding surfaces (see Fig. 6) to move over each other while, at the same time, the force pressing the two mating surfaces together is increasing. This activity results in a linear increase in the interfacial frictional sliding resistance as the stress on the interface increases, in accordance with Coulombic friction. ${ }^{17}$ The relationship between frictional sliding resistance and normal stress is given by

$$
\tau_{\mathrm{s}}=\mu \sigma_{\mathrm{N}}
$$

where $\mu$ is the static coefficient of friction and $\sigma_{\mathrm{N}}$ is the normal stress on the interface. A static coefficient of friction of 0.63 has been calculated from a least-squares linear regression of the data in Fig. 5. Similar coefficients of friction, in the range of $0.4-1.0$, have been reported for other ceramics. ${ }^{18,19}$

\section{(4) Four-Point Flexure}

(A) Unnotched Laminates: Although crack deflection and interface delaminations were apparent, all the samples fractured

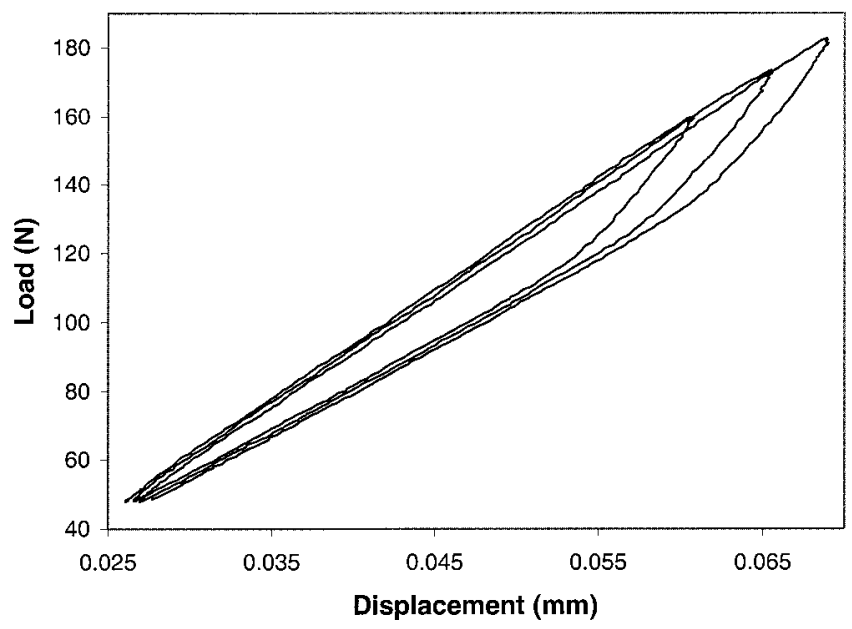

Fig. 4. Load-displacement loops from a specimen from billet 4 , showing that sliding resistance increases as load increases. (Loops from earlier in this test have been removed for clarity.)

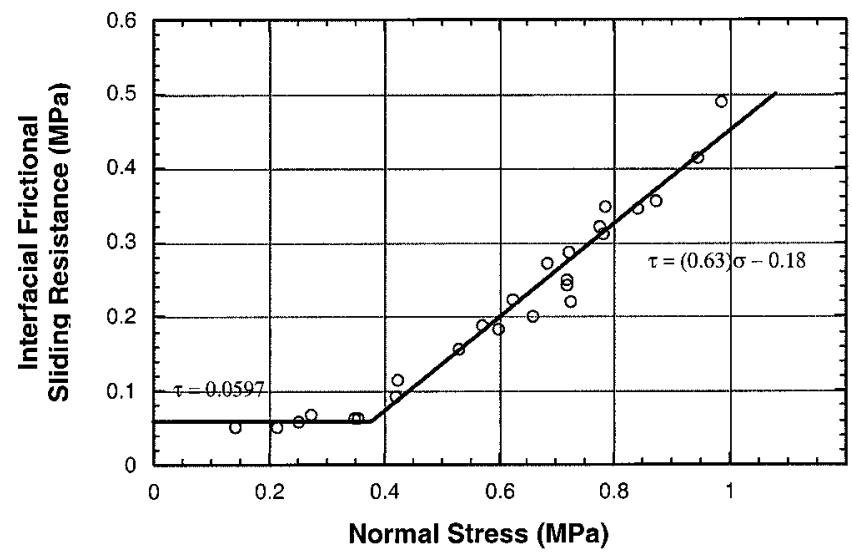

Fig. 5. Plot of normal stress versus interfacial frictional sliding resistance, showing two different behaviors. At low normal stresses, the interfacial frictional sliding resistance is constant. At high normal stresses, the interfacial frictional sliding resistance increases, in accordance with Coulombic friction. A static coefficient of 0.63 has been interpolated from the latter part of the data.

catastrophically, despite the fact that the specimens were tested under displacement control. Table III summarizes the results of these tests. With two exceptions, delamination cracks were only apparent when viewed under a microscope. The two longest delamination lengths were 1.73 and $3.6 \mathrm{~mm}$, whereas the rest were $\sim 100-200 \mu \mathrm{m}$.

(B) Notched Laminates: A representative plot of load versus specimen deflection is shown for a notched specimen in Fig. 7, and a summary of the results for all the specimens tested with notches is given in Table IV. All the notched samples exhibited noncatastrophic failure, as evidenced by load retention after the peak load. The noncatastrophic behavior displayed by the notched specimens is more typical of reported failure modes in other ceramic laminates tested in flexure, ${ }^{20,21}$ where the first load decrease is significant but the sample continues to retain load at larger displacements. Observations of the crack path confirmed that a single crack propagated through each layer in a stepwise fashion. Debonding was not observed ahead of the main crack, and multiple cracking was not observed either.

\section{Discussion}

As observed in previous reports, ${ }^{7}$ the response of alumina/ monazite laminates was highly variable. Unnotched samples were consistently brittle but exhibited crack deflection at a few of the alumina/monazite interfaces. Significant crack deflection that resulted in noncatastrophic failure occurred reliably only when the samples were notched. However, even in notched specimens, crack deflection did not occur at every interface and was sporadic. Four factors that can affect the crack deflection and debonding behavior in these laminates were considered: (i) a reaction between the alumina and monazite layers that compromises the interface; (ii) an inherently large delamination fracture energy between alumina and monazite that would make it energetically favorable for a crack to propagate through the interface rather than deflect at the interface; (iii) defects in the alumina layers, which would make it energetically favorable for a delamination crack to kink out of the interface and into the alumina layers, rather than propagate along the interface; and (iv) a large interfacial frictional sliding resistance that also can interfere with the crack path. ${ }^{22}$ Moistureassisted subcritical crack growth also may influence crack deflection; however, this phenomenon was beyond the scope of this study. The first factor did not have a role in these experiments, because, as discussed earlier, no reaction phases were detected. The other three possible causes of unreliable crack-deflection behavior are discussed further below. 

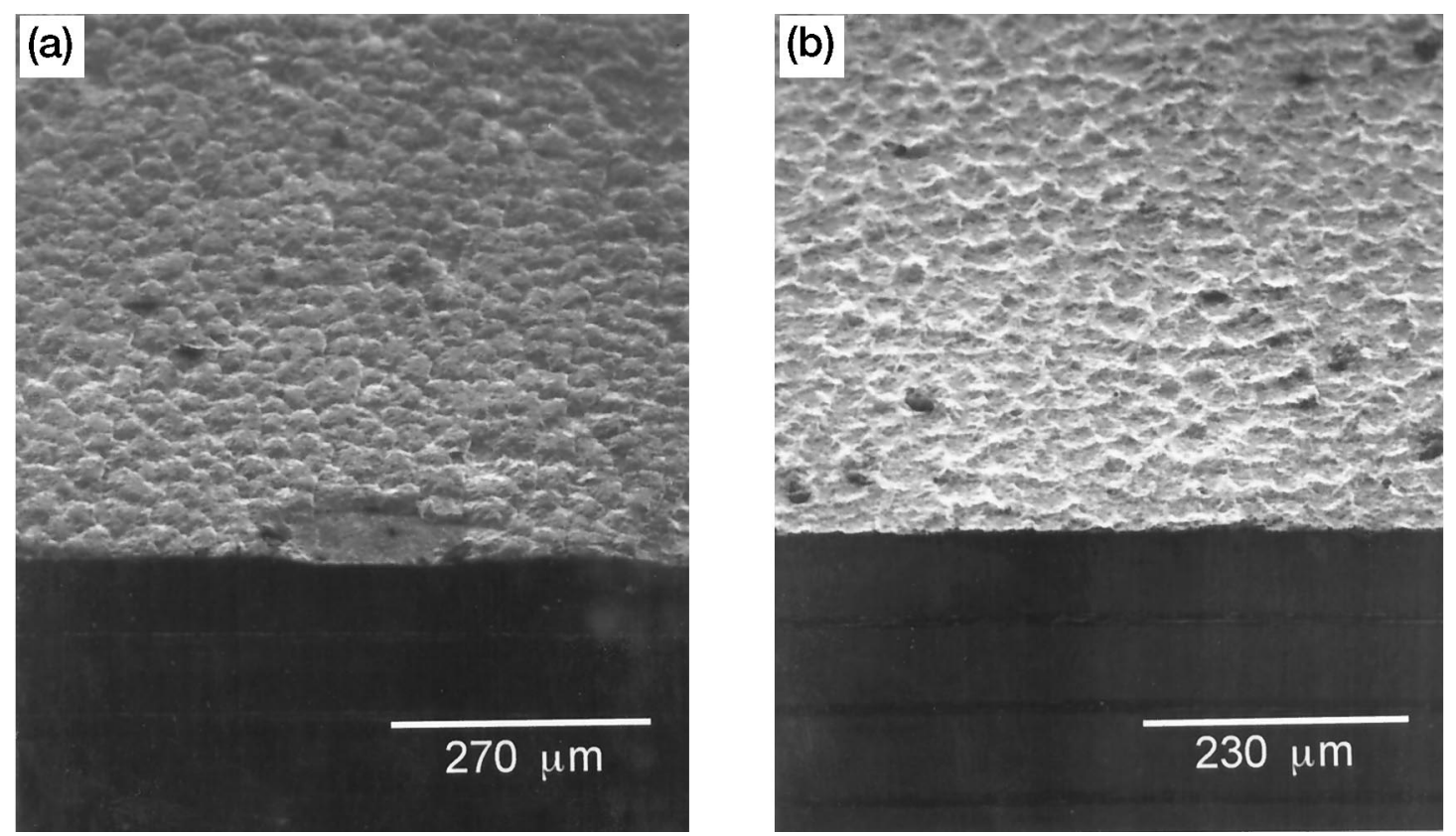

Fig. 6. Debond surfaces of a sample used for wedge and interfacial frictional sliding resistance tests from billet 4 (a) asperities on the monazite surface, and (b) asperities on the alumina surface).

Table III. Results of Four-Point Flexure of Unnotched Laminates

\begin{tabular}{cccccc}
\hline Sample & Billet & $\begin{array}{c}\text { Strength } \\
(\mathrm{MPa})\end{array}$ & $\begin{array}{c}\text { Number of delaminated } \\
\mathrm{Al}_{2} \mathrm{O}_{3} / \mathrm{LaPO}_{4} \text { interfaces }\end{array}$ & $\begin{array}{c}\text { Total number of } \\
\mathrm{Al}_{2} \mathrm{O}_{3} / \mathrm{LaPO}_{4} \text { interfaces }\end{array}$ & $\begin{array}{c}\text { Length of longest } \\
\text { delamination }\end{array}$ \\
\hline 4 & 3 & 172.9 & 3 & 16 & $3.6 \mathrm{~mm}$ \\
5 & 4 & 200.1 & 5 & 27 & $100 \mu \mathrm{m}$ \\
6 & 4 & 252.5 & 5 & 19 & $1.73 \mathrm{~mm}$ \\
\hline
\end{tabular}

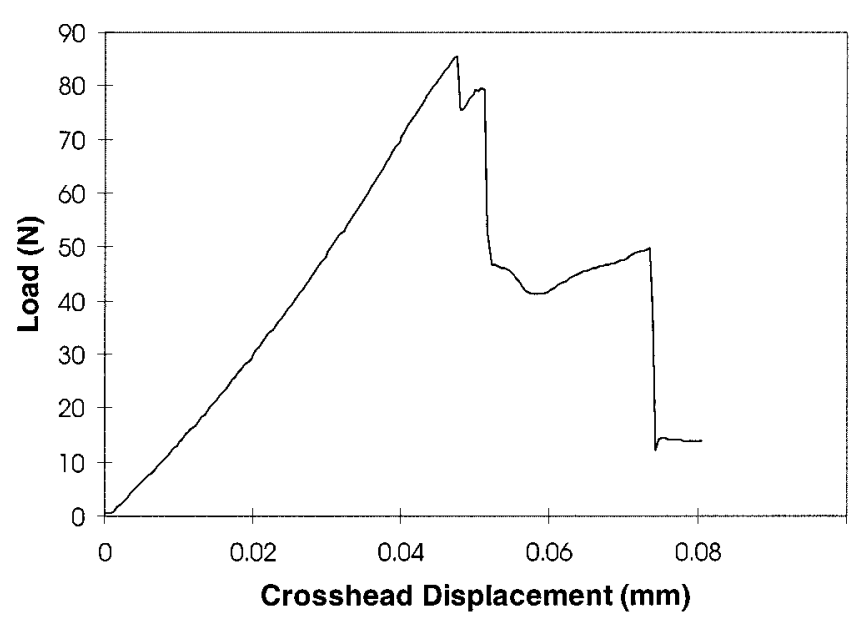

Fig. 7. Load-displacement data for a notched multilayer specimen; the test was conducted in four-point flexure.

\section{(1) Energy-Based Fracture Criteria}

Energy-based fracture criteria often are used to predict the response for a crack that is impinging on an interface. These criteria indicate that the critical delamination fracture resistance for crack deflection can be predicted based on the elastic mismatch between the two layers ${ }^{23}$ and the magnitude of the residual stress in the layers. ${ }^{24}$ Ignoring the influence of residual stress, a critical delamination fracture resistance of $<10 \mathrm{~J} / \mathrm{m}^{2}$ is predicted for this system. Tensile in-plane residual stresses occur in the alumina; therefore, ignoring residual stresses will result in a conservative estimate of the critical delamination resistance. However, the measured value of delamination resistance varied in the range of $\sim 10-15 \mathrm{~J} / \mathrm{m}^{2}$. Although a relatively high value of interfacial fracture resistance may explain why observed crack deflection was sporadic, it is important to note that the relevant fracture resistance in this case occurs at a delamination crack length of zero when the crack initially impinges on the interface. Values of the delamination resistance were measured at crack lengths of at least $3 \mathrm{~mm}$ (significantly greater in most cases), and the delamination resistance increased as the crack length increased. Thus, the experimentally measured $\Gamma_{\mathrm{i}}$ values should be considered to be an upper bound when predicting crack deflection. From the experimentally measured $\Gamma_{\mathrm{i}}$ values, the alumina/monazite interface seems to be sufficiently weak for debonding, based on the energy-based deflection criteria.

\section{(2) Defects in the Alumina Layers}

Abnormally large grains at least $22 \mu \mathrm{m}$ long were observed on the fracture surface of a bar from billet 3 when no grain-growth inhibitor was added to the alumina. These large, elongated grains can act as flaw-initiation sites within the alumina and are expected to both reduce the strength of the alumina layers and limit delamination by drawing the crack out of the interface and into the alumina layers. ${ }^{25}$ Therefore, the delamination lengths would be expected to be shorter in samples that exhibited abnormal grain growth. However, the addition of a grain-growth inhibitor to the alumina did not significantly enhance delamination (see Tables III and IV).

To address this concern, an existing model ${ }^{26}$ was applied to this system to predict the influence of flaw size in the alumina layers on delamination behavior. This model uses flaw size and the ratio of delamination fracture energy to alumina fracture energy to predict the fracture morphology of laminates. Three fracture morphologies are identified: no crack deflection, partial delamination (crack deflection, followed by crack kinking into the alumina 
Table IV. Results of Four-Point Flexure of Notched Laminates

\begin{tabular}{|c|c|c|c|c|c|c|c|c|}
\hline Sample & Billet & $\begin{array}{l}\text { Total sample } \\
\text { height }(\mathrm{mm})\end{array}$ & $\begin{array}{l}\text { Notch height } \\
(\mathrm{mm})\end{array}$ & $\begin{array}{l}\text { Work of } \\
\text { fracture } \\
\left(\mathrm{J} / \mathrm{m}^{2}\right)\end{array}$ & $\begin{array}{l}\text { Load at } \\
\text { first load } \\
\text { drop }(\mathrm{N})\end{array}$ & $\begin{array}{c}\text { Number of } \\
\text { delaminated } \\
\mathrm{Al}_{2} \mathrm{O}_{3} / \mathrm{LaPO}_{4} \\
\text { interfaces }\end{array}$ & $\begin{array}{c}\text { Total number of } \\
\mathrm{Al}_{2} \mathrm{O}_{3} / \mathrm{LaPO} \mathrm{Pa}_{4} \\
\text { interfaces above } \\
\text { notch }\end{array}$ & $\begin{array}{l}\text { Length of longest } \\
\text { ligament }(\mathrm{mm})\end{array}$ \\
\hline 7 & 3 & 4.04 & 1.27 & 288.8 & 120.8 & 3 & 13 & 5 \\
\hline 8 & 4 & 6.30 & 3.00 & 565.4 & 288.9 & 3 & 16 & 1.75 \\
\hline 9 & 4 & 4.05 & 1.95 & $97.54^{\dagger}$ & 85.4 & 7 & 13 & 6.15 \\
\hline
\end{tabular}

"Test was interrupted before sample completely failed.

layers), and complete delamination. Figure 8 shows a diagram that has been calculated for the alumina/monazite system. The assumptions made in calculating this diagram are as follows: Young's modulus of alumina $=400 \mathrm{GPa}$, Young's modulus of monazite $=$ $133 \mathrm{GPa}$, fracture energy of alumina $=20 \mathrm{~J} / \mathrm{m}^{2}$, Poisson's ratio of alumina $=$ Poisson's ratio of monazite $=0.23$, Dundurs' parameters of $\alpha=0.5$ and $\beta=0$, the delamination crack travels on the midplane of a 3-mm-high sample, and the critical flaw is oriented $90^{\circ}$ to the interface. Also, the effect of residual stresses was not considered when these calculations were made. Figure 8 indicates that the flaw size in the alumina must be smaller than $\sim 20 \mu \mathrm{m}$ to expect complete delamination behavior. The alumina/monazite laminates exhibited partial delamination behavior, which implies that the flaw size in the alumina layers was $>20 \mu \mathrm{m}$. Indeed, the average critical flaw size in the alumina, calculated from the measured strengths of the alumina bars (444 MPa for billet 5), also was $\sim 20 \mu \mathrm{m}$. Thus, because of the relatively high $\Gamma_{\mathrm{i}}$ value in this system, the flaw size in the alumina layers seems to have been large enough to influence delamination. The implication is that the flaw size in the alumina layers must be reduced further if monazite will be used as a weak interphase in this system.

\section{(3) Interfacial Frictional Sliding Resistance}

Interfacial frictional sliding resistance is a measure of the stress required to slide two surfaces, already debonded, past each other. Being able to measure the interfacial frictional sliding resistance is important, because it can influence the crack path ${ }^{22,27}$ and the energy absorbed during sliding can be a significant contribution to the total energy absorbed during fracture. Although the relationship between crack-deflection behavior and interfacial frictional sliding resistance in laminates has not been established yet, results from fiber-reinforced composites indicate that delamination is suppressed when the interfacial frictional sliding resistance increases; thus, a low frictional sliding resistance value would be preferable. $^{22}$ The measured value of the static coefficient of friction is significantly greater in this system than that measured in another laminate system that exhibits consistent crack deflection. ${ }^{26}$ Although not explored in this research, a reduction in the interfacial friction by reducing the size of the asperities may be possible. Morgan and Marshall ${ }^{7}$ and Kuo et al. ${ }^{28}$ observed much-smaller asperities on their monazite-coated sapphire fibers. The latter group measured coefficients of friction in the range of $0.2-0.27$, using fiber push-out tests.

\section{Conclusions}

The interfacial fracture energy of alumina/monazite laminates was measured using two independent methods, which gave an average measured interfacial fracture energy of $\sim 14 \mathrm{~J} / \mathrm{m}^{2}$ but also showed that the fracture energy is dependent on the crack length. At similar crack lengths, these results were comparable to those reported in earlier work. ${ }^{7}$ The interfacial frictional sliding resistance in the alumina/monazite laminates increased as the normal stress increased. A simple Coulombic friction model gave a coefficient of static friction of 0.63 . Crack deflection occurred sporadically in flexure tests of the alumina/monazite laminates. The average strength of the unnotched flexure bars was 208.5 $\mathrm{MPa}$; all these bars exhibited sporadic crack deflection but failed catastrophically. The notched flexure bars also exhibited sporadic crack deflection; however, they failed noncatastrophically.

Although the measured delamination fracture energy should be low enough to make crack deflection energetically favorable, fracture behavior in the alumina/monazite system seems to be sensitive to flaws in the alumina layers. An existing model was used to show that the critical flaw size that was needed to ensure crack deflection in this system must be less than $\sim 20 \mu \mathrm{m}$. Also, the sliding resistance measured in this system is considerably larger than that measured in another laminate system that exhibited abundant crack deflection. ${ }^{26}$ Results from fiber-reinforced composites indicate that delamination is suppressed when the interfacial frictional sliding resistance increases; thus, a lower value of

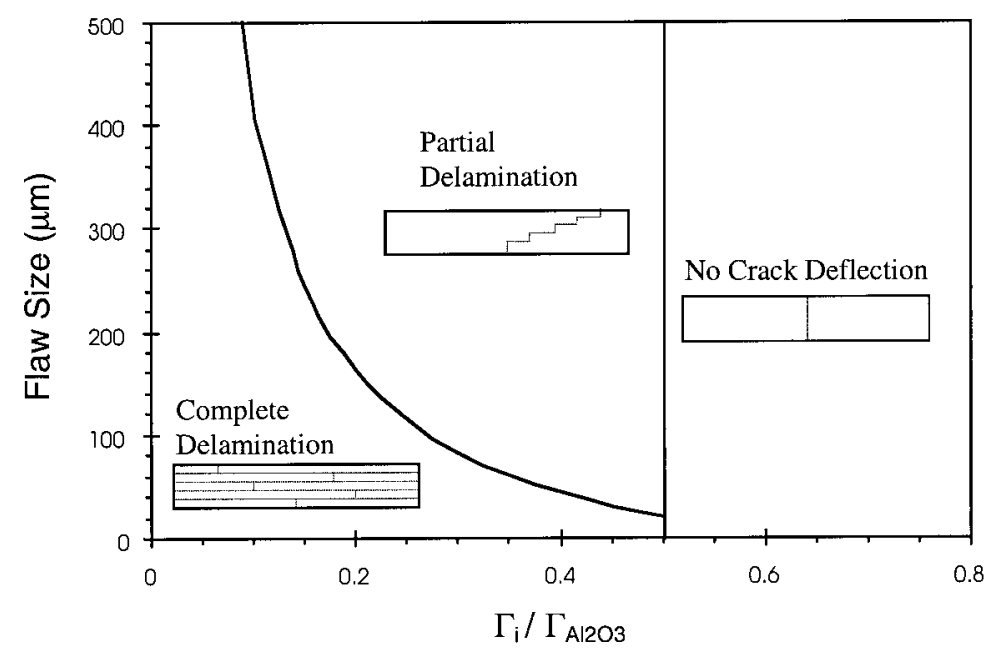

Fig. 8. Calculated delamination behavior for alumina/monazite multilayer laminates as a function of flaw size and the ratio of initial interfacial fracture energy to the fracture energy of alumina. 
frictional sliding resistance (by reducing the asperity size) would be preferable.

Achieving consistent crack deflection may be possible using monazite as an interphase in oxide composites if the roughness of the monazite/alumina interface and the size of the flaws in the alumina could be reduced. Composites made from single-crystal, amorphous, or very-fine-grained reinforcement materials (such as those used for many commercially available reinforcement materials) may have more potential in this regard. The use of such reinforcement fibers would eliminate flaw-size concerns and also reduce concerns about the interface roughness.

\section{Acknowledgments}

The authors wish to thank Dr. Peter Morgan for providing the rhabdophane used to fabricate the materials used in this study and Drs. Peter Morgan, Robert Housley, and David Marshall for their advice and assistance.

\section{References}

${ }^{1}$ W. J. Clegg, K. Kendall, N. M. Alford, T. W. Button, and J. D. Birchall, "A Simple Way to Make Tough Ceramics," Nature (London), 347, 455-57 (1990).

${ }^{2}$ D. B. Marshall and A. G. Evans, "Failure Mechanisms in Ceramic-Fiber/CeramicMatrix Composites," J. Am. Ceram. Soc., 68 [5] 225-31 (1985).

${ }^{3}$ D. Kovar, B. H. King, R. W. Trice, and J. W. Halloran, "Fibrous Monolithic Ceramics," J. Am. Ceram. Soc., 80 [10] 2471-87 (1997).

${ }^{4}$ P. E. D. Morgan and D. B. Marshall, "Functional Interfaces for Oxide/Oxide Composites," Mater. Sci. Eng. A, A162, 15-25 (1993).

${ }^{5}$ Y. Hikichi, K. Hukuo, and J. Shiokawa, "Solid State Reactions between Rare Earth Orthophosphates and Oxide," Bull. Chem. Soc. Jpn., 53, 1455-56 (1980).

${ }^{6}$ D. B. Marshall, P. E. D. Morgan, R. M. Housley, and J. T. Cheung, "HighTemperature Stability of the $\mathrm{Al}_{2} \mathrm{O}_{3}-\mathrm{LaPO}_{4}$ System," J. Am. Ceram. Soc., 81 [4] 951-56 (1998).

${ }^{7}$ P. E. D. Morgan and D. B. Marshall, "Ceramic Composites of Monazite and Alumina," J. Am. Ceram. Soc., 78 [6] 1553-63 (1995).

${ }^{8}$ D.-H. Kuo and W. M. Kriven, "Chemical Stability, Microstructure and Mechanical Behavior of $\mathrm{LaPO}_{4}$-Containing Ceramics," Mater. Sci. Eng. A, A210, 123-34 (1996).

${ }^{9}$ W. R. Cannon, J. R. Morris, and K. R. Mikeska, "Dispersants for Nonaqueous Tape Casting"; pp. 161-74 in Advances in Ceramics, Vol. 19, Multilayer Ceramic Devices. Edited by J. B. Blum and W. R. Cannon. American Ceramic Society, Westerville, $\mathrm{OH}, 1986$.
${ }^{10}$ C. Van Hoy, A. Barda, M. Griffith, and J. W. Halloran, "Microfabrication of Ceramics by Co-extrusion," J. Am. Ceram. Soc., 81 [1] 152-58 (1998).

${ }^{11}$ P. G. Charalambides, J. Lund, A. G. Evans, and R. M. McMeeking, "A Test Specimen for Determining the Fracture Resistance of Bimaterial Interfaces," J. Appl. Mech., 56, 77-82 (1989).

${ }^{12}$ Z. Suo and J. W. Hutchinson, "Sandwich Test Specimen for Measuring Interface Crack Toughness," Mater. Sci. Eng. A, A107, 135-43 (1989).

${ }^{13}$ D. Johnson-Walls, D. B. Marshall, A. G. Evans, M. D. Drory, and K. T. Faber, "Evaluation of Reliability of Brittle Components by Thermal Stress Testing," J. Am. Ceram. Soc., 68 [7] 363-67 (1985).

${ }^{14}$ D. Kovar and M. D. Thouless, "Simple Method for Measuring Frictional Sliding Resistance and Energy Dissipation in Layered Ceramics," J. Am. Ceram. Soc., 80 [3] 673-79 (1997).

${ }^{15}$ P. E. D. Morgan, D. B. Marshall, and R. M. Housley, "High-Temperature Stability of Monazite-Alumina Composites," Mater. Sci. Eng. A, A195, 215-22 (1995).

16“Standard Test Method for Water Absorption, Bulk Density, Apparent Porosity, and Apparent Specific Gravity of Fired Whiteware Products," ASTM Standard C373-72, 1982 Annual Book of ASTM Standards, American Society for Testing and Materials, Philadelphia, PA (now in West Conshohocken, PA).

${ }^{17}$ J. W. Hutchinson and H. M. Jensen, "Models of Fiber Debonding and Pullout in Brittle Composites with Friction," Mech. Mater., 9, 139-63 (1990).

${ }^{18}$ T. E. Fischer and W. M. Mullins, "Ceramics, Friction, and Chemistry," CHEMTECH, 27-31 (1993).

${ }^{19}$ H. E. Sliney and C. Dellacorte, "The Friction and Wear of Ceramic/Ceramic and Ceramic/Metal Combinations in Sliding Contact," Lubr. Eng., 50 [7] 571-76 (1994).

${ }^{20}$ A. J. Phillipps, W. J. Clegg, and T. W. Clyne, "Fracture Behaviour of Ceramic Laminates in Bending-II. Comparison of Model Predictions with Experimental Data," Acta Metall. Mater., 41 [3] 819-27 (1993).

${ }^{21}$ A. J. Phillipps, W. J. Clegg, and T. W. Clyne, "The Failure of Layered Ceramics in Bending and Tension," Composites (Guildford, UK), 25 [7] 524-33 (1994).

${ }^{22}$ M. D. Thouless and A. G. Evans, "Effects Pull-Out on the Mechanical Properties of Ceramic-Matrix Composites," Acta Metall., 36 [3] 517-22 (1988).

${ }^{23}$ M.-Y. He and J. W. Hutchinson, "Crack Deflection at an Interface Between Dissimilar Elastic Materials," Int. J. Solids Struct., 25 [9] 1053-67 (1989).

${ }^{24}$ H. Y. He, A. G. Evans, and J. W. Hutchinson, "Crack Deflection at an Interface Between Dissimilar Elastic Materials: Role of Residual Stresses," Int. J. Solids Struct., 31 [24] 3443-55 (1994).

${ }^{25}$ M.-Y. He, A. Bartlett, and A. G. Evans, "Kinking of a Crack Out of an Interface: Role of In-Plane Stress," J. Am. Ceram. Soc., 74 [4] 767-71 (1991).

${ }^{26}$ D. Kovar, M. D. Thouless, and J. W. Halloran, "Crack Deflection and Propagation in Layered Silicon Nitride/Boron Nitride Ceramics," J. Am. Ceram. Soc., 81 [4] 1004-12 (1998)

${ }^{27}$ K. S. Chan, M.-Y. He, and J. W. Hutchinson, "Cracking and Stress Redistribution in Ceramic Layered Composites," Mater. Sci. Eng. A, A167, 57-64 (1993).

${ }^{28}$ D.-H. Kuo, W. M. Kriven, and T. J. Mackin, "Control of Interfacial Properties through Fiber Coatings: Monazite Coatings in Oxide-Oxide Composites," J. Am. Ceram. Soc., 89 [12] 2987-96 (1997). 